\title{
Acceptability of contraceptive implants at the maternity ward of the Matam Communal Medical Center
}

\author{
Conte Ibrahima ${ }^{1 *}$, Soumah Aboubacar Fodé Momo ${ }^{1}$, Diallo Boubacar Alpha ${ }^{2}$, \\ Sow Ibrahima Sory ${ }^{2}$, Camara Aminata ${ }^{2}$, Diallo Abdourahamane ${ }^{1}$, Sy Telly ${ }^{1}$, Keita Namory ${ }^{2}$
}

\begin{abstract}
${ }^{1}$ Department of Obstetric Gynecology of The Ignace Deen National Hospital of the University Hospital of Conakry, Gamal Abdul Nasser University, Conakry, Guinea

${ }^{2}$ Department of Obstetric Gynecology of The Donka National Hospital of the University Hospital of Conakry, Gamal Abdul Nasser University, Conakry, Guinea
\end{abstract}

Received: 18 December 2021

Revised: 23 January 2022

Accepted: 24 January 2022

\author{
*Correspondence: \\ Dr. Conte Ibrahima, \\ E-mail: conteib1976@gmail.com
}

Copyright: (c) the author(s), publisher and licensee Medip Academy. This is an open-access article distributed under the terms of the Creative Commons Attribution Non-Commercial License, which permits unrestricted non-commercial use, distribution, and reproduction in any medium, provided the original work is properly cited.

\begin{abstract}
Background: World Health Organization (WHO), defines contraception as "the use of agents, devices, methods or procedures to decrease the likelihood of conception or avoid it". In Africa, only $24 \%$ of women of childbearing age have access to a modern contraceptive method. The objective of the study was to determine the frequency of use of the contraceptive implant, to describe the socio-demographic characteristics of the users, to identify the reasons for the choice of the method and to assess the degree of satisfaction of the clients.

Methods: The study was conducted at the Matam Communal Medical Center on level 2 of the health pyramid in Guinea. This was a 12-month cross-sectional, descriptive and analytical study (June 2017 to May 2018), including all women admitted for desire for contraception and who agreed to choose the implant as a contraceptive method.

Results: The study involved 512 clients. The proportion of female users was $26.21 \%$. The average age was 27.8 years, the main users were women of liberal trade, married, multiparous. The main reasons for choice cited by clients were the effectiveness and long duration of action of the method, i.e. $35.2 \%$ and $30.9 \%$ respectively. The majority of providers of the method were represented by midwives $(73.3 \%)$ and the degree of client satisfaction with the method was $97 \%$.

Conclusions: The implant is a long-acting method of contraction. It is frequently used at the Communal Medical Center of Matam. Its efficient use would involve effective counselling.
\end{abstract}

Keywords: Implant, Contraception, Effectiveness, Satisfaction

\section{INTRODUCTION}

Contraceptive implants are one of the most effective methods of family planning available. Implants are small, thin, flexible sticks that are inserted just below the skin of the woman's arm. According to the WHO, the effective use of contraceptives would prevent an estimated 2.7 million infant deaths and the loss of 60 million healthy lives while promoting family planning could reduce poverty, hunger and prevent $32 \%$ of maternal deaths nearly $10 \%$ of child deaths. ${ }^{1}$ Scientific evidence of the acceptability of longacting reversible contraception and successful use is lacking in a population that generally opts for short-acting methods. ${ }^{2}$ In order to promote women's reproductive health and prevent the risk of unwanted pregnancies, the use of long-acting reversible contraceptive methods is paramount and remains an important indicator that reflects access to reproductive health services. ${ }^{3,4}$ Improving knowledge of and access to these methods is a public 
health imperative and a social justice imperative. ${ }^{5}$ Unfortunately, despite these benefits, implants are underused; less than $0.7 \%$ In the United States. ${ }^{6}$ In subSaharan Africa, where the burden of maternal mortality is the highest, this prevalence is still very low, $0.4 \%$ in Nigeria. ${ }^{7}$ In Guinea, contraceptive prevalence has evolved very slowly, during the IUD and subcutaneous implants has remained very low (1\%)8.

\section{METHODS}

The study was carried out at the Gynecology-Obstetrics Department of the Matam Communal Medical Center, which is a level II hospital in the country's health pyramid. This was a cross-sectional, descriptive and analytical study of a period of 6 months, from June to May, 2018. The study included all women admitted for desire for family planning and who agreed to choose the implant for FP method and who received the method. Those who did not agree to participate or who did not choose the method were excluded. The sample size was calculated using the Lorenz formula: $\mathrm{N}=\mathrm{Za} 2 \mathrm{PQ}$ (where: $\mathrm{N}=$ acceptable sample size in each group [calculated value $=95.04$ ]; $\mathrm{a}=$ statistical significance level $\mathrm{D} 2 ; \mathrm{Za}=$ normal distribution value $=$ 1.96 for $\mathrm{a}=0.05 ; \mathrm{P}=$ prevalence of female users $=24.3 \%$; $\mathrm{Q}=1$ - P; D = level of accuracy $=10 \%$ ). The minimum acceptable sample size was 240 patients. The variables studied were epidemiological and clinical. The epidemiological and clinical variables are: age, occupation, level of education, parity, reasons for choice, satisfaction, side effects, reasons for withdrawing from the method. The data was entered and analyzed using epi info software version 6 . The statistical test used is Chi2, with a level significance set at $\mathrm{p}<0.05$.

\section{Consent}

Before carrying out the study, we obtained the agreement of the administrative authorities of the service, the clients gave their consent to participate in the study, confidentiality was respected throughout the data collection procedure and the results were used for strictly scientific purposes.

\section{RESULTS}

\section{Frequency of use of the implant}

During the study period, we recorded 1953 users of family planning methods of all methods combined, among them 512 had chosen the implant as a method of birth spacing or a proportion of $26.21 \%$.

The average age of female clients was 27.8 years with the extremes of 18 to 39 years. These clients were mainly aged 20-24 years, i.e. a proportion of $28.3 \%$, exercising a liberal profession and pupils and/or students, i.e. $42 \%$ and $25.2 \%$ respectively. Almost half $(49.8 \%)$ of these clients had secondary education and $38 \%$ had primary education.
Table 1: Socio-demographic characteristics of clients.

\begin{tabular}{|lll|}
\hline \multicolumn{1}{l}{ Actual } & $\%$ \\
\hline Age & & \\
\hline $15-19$ years & 77 & 15.0 \\
\hline $20-24$ years & 145 & 28.3 \\
\hline $25-29$ years & 110 & 21.7 \\
\hline $30-34$ years & 142 & 27.5 \\
\hline 35 years and over & 38 & 7.5 \\
\hline Profession & & \\
\hline Housewives & 104 & 20.3 \\
\hline Liberal functions & 215 & 42.0 \\
\hline Pupils/students & 129 & 25.2 \\
\hline Employees & 63 & 12.5 \\
\hline $\begin{array}{l}\text { Level of education } \\
\text { uneducated }\end{array}$ & 0 & 0.0 \\
\hline Primary & 195 & 38.0 \\
\hline Secondary & 255 & 49.8 \\
\hline Upper & 62 & 12.2 \\
\hline Marital status & & \\
\hline Married & 215 & 42.0 \\
\hline Single & 237 & 46.3 \\
\hline Divorced & 60 & 11.7 \\
\hline Total & 512 & 100 \\
\hline
\end{tabular}

Table 2: Obstetrics characteristics.

\begin{tabular}{|lll|}
\hline Parity & Efficacy & $\%$ \\
\hline Nulliparous & & \\
\hline Primipare & 94 & 18.4 \\
\hline Paucipare & 125 & 24.4 \\
\hline Multiparous & 163 & 31.9 \\
\hline Total & 130 & 25.3 \\
\hline
\end{tabular}

Table 3: Distribution of clients according to the reasons for the choice of implant.

\begin{tabular}{|l|cc|}
\hline Reason for choice & Efficacy & $\%$ \\
\hline Effectiveness of the method & 389 & 76.1 \\
\hline Long duration of action & 334 & 65.2 \\
\hline Discretion advice from a & 164 & 32.1 \\
friend & 275 & 53.7 \\
\hline Advice from a neighbour & 110 & 21.4 \\
\hline Total & 512 & 100 \\
\hline
\end{tabular}

Regarding marital status, the results showed that singles were the largest users of the implant in our sample at $46.3 \%$ followed by married women with $42.0 \%$. Paucipares and primiparous women were the most numerous among clients with proportions of $31.9 \%$ (163) and $24.41 \%$ (125) respectively.

The effectiveness of the method and the long duration of action were the main reasons for choosing the implant in our study: $76.1 \%$ and $65.2 \%$ respectively. 
Table 4: Medical providers of insertion of the method and the degree of satisfaction of the clients.

\begin{tabular}{|c|c|c|}
\hline & Efficacy & $\%$ \\
\hline \multicolumn{3}{|c|}{ Method insertion providers } \\
\hline Doctor & 77 & 25.0 \\
\hline Midwife & 145 & 73.4 \\
\hline Nurse & 110 & 1.6 \\
\hline \multicolumn{3}{|c|}{ Level of client satisfaction } \\
\hline Satisfied & 498 & 97.2 \\
\hline Not satisfied & 14 & 2.8 \\
\hline Total & 512 & 100 \\
\hline
\end{tabular}

Table 5: Effects.

\begin{tabular}{|lll|}
\hline & Efficacy & $\%$ \\
\hline Effects & & \\
\hline Spotting & 282 & 55.0 \\
\hline Weight gain & 144 & 28.2 \\
\hline Amenorrhea & 81 & 15.9 \\
\hline Pain at the insertion site & 5 & 0.9 \\
\hline Total & 512 & 100 \\
\hline
\end{tabular}

Table 6: Distribution of clients according to withdrawal and reasons for withdrawal from the method.

\begin{tabular}{|lll|}
\hline \multicolumn{2}{|c|}{ Efficacy } & $\%$ \\
\hline \multicolumn{2}{|l|}{ Removing the method } \\
\hline Yes & 42 & 8.2 \\
\hline No & 470 & 91.8 \\
\hline Reasons for removing the method \\
\hline Desire for pregnancy & 30 & 71.4 \\
\hline Choosing another method & 6 & 13.2 \\
\hline Effects & 5 & 12.1 \\
\hline Method failed & 1 & 3.3 \\
\hline
\end{tabular}

Nearly 3/4 (73.4\%) of implants were inserted by midwives and only $1 / 4(25 \%)$ by doctors. The results showed that almost all $(97.2 \%)$ of the clients were satisfied with the method compared to $2.8 \%$ of the unsatisfied clients. Spotting and weight gain were the top side effects found during our research at $55 \%$ and $28.2 \%$ respectively.

The continuity rate of the method was very high at almost $92 \%$. The main reason for withdrawal was due to desire for a new pregnancy $(71.4 \%$ of cases).

\section{DISCUSSION}

\section{Frequency of use of the implant}

Our proportion of female users is $26.21 \%$. The frequency of contraceptive implant use nationwide in Guinea is $2 \%$ among women in union. ${ }^{9}$ This high rate of the method in our study could be justified by the following elements: the first is a hospital frequency, and the second is the result of the success of the various awareness campaigns as well as the quality of the delivery offered by the health personnel of the service.

\section{Socio-demographic characteristics of clients}

Age

The average age of our users was 27.8 years, and clients aged 20-24 were the most numerous among clients with a proportion of $28.3 \%$, followed by that of 30-34 years or $27.5 \%$ (Table1). In research conducted in South Africa, Beesham I and Coll. report that the average age of their users was 28 years with extremes of 19 and 44 years. ${ }^{10}$

\section{Occupation}

Our survey shows that female clients in the liberal profession and pupils were the most numerous in our sample, i.e. $42 \%$ and $25.2 \%$ respectively (Table 1 ). This could be explained by the proximity between the CMC and the large market of Madina, in addition these women would like to space the births in order to fruit their activity or continue their study. In a study carried out in MbujiMayi (DRC), Mukengeshayi et al found that 41.4\%; of their users were merchants; and $32.1 \%$ were housewives. ${ }^{11}$ This result is different from that of Koné B and al. who reported a predominance of housewives with a proportion of $65 \% .{ }^{12}$ Our result could be justified by the fact that these women with a liberal profession are more and more numerous in the general population, but also these women do not have a wide knowledge of their ovulation period so the way for them to avoid unwanted pregnancies is contraception.

\section{Level of education}

Almost half $(49.8 \%)$ of our clients had secondary education and $38 \%$ had primary education (Table1). This predominance of the secondary level of education was found by Mukengeshayi et al or more than half of their clients $(55.4 \%)$ had a high school education; $32.1 \%$ had a primary level. ${ }^{11}$ In contrast, in Zambia Mutombo et al report that more than half of their clients $(54.7 \%)$ had a primary level of education and $36 \%$ had a secondary level. ${ }^{13}$ Our result could be justified by the fact that this level contains many more adolescent girls, and adults who have stopped studying most often for reasons of early marriage, or lack of support.

\section{Marital status}

The results showed that single women were the largest users of the implant in our sample at $46.3 \%$ followed by married women with $42.0 \%$ (Table 1). This result could be justified by the fact that our society stigmatizes single mothers and that any pregnancy out of wedlock and considered contrary to the vallaires of society, and leads to 
a kind of contempt for the mother. The same finding was made in South Africa where Beesham et al report that $69.2 \%$ of the clients in their sample were single. ${ }^{10}$ On the other hand, Keita et al find that the main users of modern methods of contraception were married women with a proportion of $90.71 \% .^{14}$

\section{Obstetric characteristics}

In our study, we found that most clients were either paucipare or primiparous with proportions of $31.9 \%$ (163) and $24.41 \%$ (125) respectively (Table 2). This result could be justified on the one hand by the manifest desire of these women to space births, on the other hand by the success of the various awareness-raising campaigns on long-acting contraceptive methods not only in our service but also throughout the country. This result is similar to that of Mutombo et al who reported in their study a high proportion $(37 \%)$ of women who had three or four children. ${ }^{15}$ Unlike that of Lorenzo et al who reported in their study that $159(42.7 \%)$ were nulliparous. ${ }^{16}$

\section{Reasons for the choice of implant}

The main reasons for choosing the implant were the effectiveness of the method and the long duration of action respectively $76.1 \%$ and $65.2 \%$ (Table 3 ). Identical reasons for choice, however, at different proportions, have been reported in South Africa where, $64.2 \%$ of women chose to use NXT Implant because it is a long-acting method, and half $50 \%$ because they did not want to return frequently to the clinic for follow-up. ${ }^{10}$

This enthusiasm for the use of the method could be due to the impact of the implementation of awareness campaigns carried out among populations on the benefits of longacting contraceptive methods.

\section{Medical providers of insertion of the method and the degree of satisfaction of the clients}

\section{Medical provider who inserted the implant}

Our results show that nearly $3 / 4$ (73.4\%) of implants were inserted by midwives and $1 / 4$ by doctors (Table 4 ). This could be explained by the fact that midwives often do counselling and at the same time have the skills for integration, not to mention gender issues that put clients in confidence between themselves and midwives.

\section{Client satisfaction rate}

Almost all $(97.2 \%)$ of clients were satisfied with the method compared to $2.8 \%$ of unsatisfied clients (Table 4 ). This result could be justified by the effectiveness and discretion of the contraceptive method. This result could be justified by the effectiveness and discretion of the contraceptive method. Sergeant F and Coll. reported in their study that $81 \%$ of female users were generally satisfied with contraceptive implants. ${ }^{17}$

\section{Side effects}

Spotting and weight gain were the main side effects observed in our research, respectively $55 \%$ and $28.2 \%$ (Table 5). In contrast, in a study conducted in France, Martin et al reported that the main side effects were amenorrhoea (50\%), weight gain $(30 \%)$ and $\operatorname{mood}$ disorders $(19 \%){ }^{18}$

\section{Reasons for removal of the implant}

The rate of continuity of the method was very high at almost $92 \%$. It was found that very few of our clients withdrew their implants, mainly because they wanted to become pregnant again (71.4\% of cases) or chose another method (13.2\% of cases) (Table 6$)$. A study conducted in Madagascar by Ralisatat et al showed that the main reasons for clients to remove the implant were menstrual disorders, personal convenience for pregnancy, weight gain, and in rare cases method failure. ${ }^{19}$

\section{Limitation of the study}

This is a hospital-based study that cannot be extended to the general population and the resulting practical conclusions are only applicable to the target population defined above.

\section{CONCLUSION}

In short, the contraceptive implant is one of the reversible contraceptive methods most used by women. Clients were generally multiparous. The effectiveness and duration of action of the method were the reasons for choice most mentioned by the clients. Almost all clients were satisfied with the use of the method as a means of birth spacing. The desire for pregnancy and the client's willingness to change methods were the main reasons for withdrawing from the method. However, a good information and awareness campaign on side effects would be necessary in order to reduce the number of implant removals. Since the small size of our sample does not allow conclusions to be drawn at the national level, multicentre studies are needed to define the contours of this question and identify the determinants of the contraceptive implant in Guinea.

Funding: No funding sources

Conflict of interest: None declared

Ethical approval: The study was approved by the Institutional Ethics Committee

\section{REFERENCES}

1. Cleland J, Bernstein S, Ezeh A, Faundes A, Glasier A, Innis J. Family planning: the unfinished agenda. Geneva. Lancet. 2006;368(9549):1810-27.

2. Hubacher D, Spector H, Monteith C, Chen P-L, Hart C. Long-acting reversible contraceptive acceptability and unintended pregnancy among women presenting for short-acting methods : a randomized patient 
preference trial. Am J Obstet Gynecol. Févr. 2017;216(2):101-9.

3. Yalew SA, Zeleke BM, Teferra AS. Demand for long acting contraceptive methods and associated factors among family planning service users, Northwest Ethiopia: a health facility based cross sectional study. BMC Res Notes. 2015;8(29):10.

4. Vu LTH, Oh J, Bui QTT, Le ATK. Use of modern contraceptives among married women in Vietnam: a multilevel analysis using the Multiple Indicator Cluster Survey (2011) and the Vietnam Population and Housing Census (2009). Glob Health Action. 2016;9(10):3402.

5. Jenny AH, Renée D, Kramer, Kristin M, Ryder. Provider bias in long-acting reversible contraception (LARC) promotion and removal: perceptions of young adult women. Am J Santé publique. 2016;106(11):1932-7.

6. Zeal C, Jenny A, Higgins, Shaunna R, Newton. Patient-perceived autonomy and long-acting reversible contraceptive use: a qualitative assessment in a midwestern, university CommunityBioResearch open access. 2018;7(1):25-32.

7. Reiss K, Penfold S, Alabi O, Ali M, Hopkins K, Ngo TD, et al. Safety, Quality, and Acceptability of Contraceptive Subdermal Implant Provision by Community Health Extension Workers Versus Nurses and Midwives in Nigeria: Protocol for a QuasiExperimental, Noninferiority Study. JMIR Res Protoc. 2018;7(3):67.

8. Ministry of Health and Public Hygiene. National Directorate of Family Health and Nutrition. National Action Plan for Repositioning Family Planning in Guinea 2014-2018.

9. National Institute of Statistics (NIS) and ICF. 2018. Guinea Demographic and Health Survey 2018. Conakry, Guinea, and Rockville, Maryland, USA: INS and ICF.

10. Beesham I, J Smit, M Beksinska, M Panday, Makatini $\mathrm{V}$. Reasons for requesting removal of the hormonal implant, Implanon NXT, at an urban reproductive health clinic in KwaZulu-Natal, South Africa. 2019;109(10):750-5.

11. Ntambue MA, Tshiala RN, Malonga FK, Ilunga TM, Kamonayi JM, Kazadi ST et al. Use of modern contraceptive methods in the Democratic Republic of Congo: prevalence and barriers in the Dibindi health zone in Mbuji-Mayi Pan African Medical Journal. 2016;26:199.

12. Koné B, Lankoande J, Ouédraogo MR, Ouédraogo A, Bonane B, Touré B et al. Contraception with subcutaneous levonorgestrel implants (Norplant ${ }^{\circledR}$ ): African experience in Burkina Faso. Méd Afr Noire 1999;46(3):136-9.

13. Namuunda $M$, Bakibinga $P$. The effect of joint contraceptive decisions on theuse of Injectables, Long-Acting and Permanent methods (ILAPMs) amongmarriedfemale (15-49) contraceptive users in Zambia: a cross-sectional study. Reproductive Health. 2014;51:1-8.

14. Mamadou K, Fomba S, Tall S, Alou S, Mamadou D, Djoukou KN et al. L'Utilisation des Méthodes Contraceptives Modernes au Centre de Santé de Référence de la Commune VI du District de Bamako. Health Sci Dis. 2020;21(10):82-6.

15. Mutombo N, Bakibinga $P$. The effect of joint contraceptive decisions on these of Injectables, LongActing and Permanent methods (ILAPMs) amongmarriedfemale (15-49) contraceptive users in Zambia : a cross-sectional study. Reproductive Health. 2014;11:51.

16. Arribas-Mir L, Rueda-Lozano D, Agrela-Cardona M, Cedeno-Benavides T, Olvera-Porcel C, BuenoCavanillas A. Insertion et expérience de suivi de 3 ans de 372 implants contraceptifs sous cutanés d'étonogestrel par des médecins de famille à Grenade Espagne. 2009 ;80(5):457-62.

17. Sergent F, Clamogeran C, Bastard AM, Verspyck E, Marpeau L. Acceptability of the contraceptive implant containing Etonogestrel (Implanon). J Gynecol Obstet Biol Reprod Paris. 2004;33(5):407-15.

18. Martin C, Tanguy M, Aspeele F, Fanello S. Tolerance of the contraceptive implant by prescription context (after abortion or not): Prospective study on 127 consultants. J Gynecol Obstet Biol Reprod (Paris). 2010;39(8):632-6.

19. Ralisata L, Ravolamanana, Randaoharison PG, Razafintsalama DL. Contraception with subcutaneous levonorgestrel implants (Norplant ${ }^{\circledR}$ ) at the University Hospital of Mahajanga Madagascar. Médecine d'Afrique Noire. 2000;47(10):410-5.

Cite this article as: Ibrahima $\mathrm{C}$, Momo SAF, Alpha DB, Sory SI, Aminata C, Abdourahamane D et al. Acceptability of contraceptive implants at the maternity ward of the Matam Communal Medical Center. Int J Reprod Contracept Obstet Gynecol 2022;11:343-7. 